\title{
APPLICATION OF FRACTAL GEOMETRY TO STUDY THE GEOLOGICAL STRUCTURE OF THE ZARIN PLAIN (PLAIN RAZAK)
}

\author{
Khadijeh Faridi $\mathrm{Nia}^{1} \uparrow---$ Asghar Teymoorian ${ }^{2}$--- Mojtaba Babaei ${ }^{3}$ \\ ${ }^{\prime}$ M.Sc. degree on Geophysics, Hamedan Branch, Islamic Azad University, Hamedan, Iran \\ ${ }^{2,3}$ Departments of Geophysics, Hamedan Branch, Islamic Azad University, Hamedan, Iran
}

\begin{abstract}
One of the most important steps to obtain the specified density Bouguer anomaly corrections for the topography of the page Bouguer is the most commonly used way in which the relationship between topography and Bouguer anomaly in the method assumes that topography of the rigid shell instead Isoztasi balance is maintained. The method to determine the density of Bouguer provided by fractal analyze these are the lowest density dependence the topography of the area is considered as the optimal density and the fractal relationship to the topography of the fractal dimension using the Bouguer anomaly.
\end{abstract}

Keywords: Bouguer anomaly, Optimal density, Fractal dimension, Zarin plain.

Received: 28 August 2014/ Revised: 20 September 2014/ Accepted: 24 September 2014/ Published: 29 September 2014

\section{INTRODUCTION}

Zarin Plain in the southern part of the province. In the past, in the name of the plain Razak, known as the has been chosen and about $40 \mathrm{~km}$ southeast Jahrom and the height of the average of the plain about 830 meters above sea level, the study of the $22 \times 25 \mathrm{sq}$. km (1) the mountainous region syncline-anticline and syncline compound emerged Some are flat plains have become. Some anticlines to flat plains have become part of the Golan Heights, and also because of the erosion of the kind of rocks and tectonic region has hills. A general and trend page stratum in central China's hilly and there is NW-SE. Surrounding plains are Asmari-Jahrom, Bakhtiari conglomerate, Gori membrane, Tabriz, Mishan and domes salt is in the formation Alluvial plain is covered.

Bakhtiari Formation: conglomerates slumber for Bakhtiari formations (Firestone) and calcareous sandstones which unconformable on sediments in the Gulf of Lorestan, Khuzestan and 
Bakhtiari Mountains have been used. This name consists of conglomerates like Gulf as well. Formation approximately $554 \mathrm{~m}$ is thick sand. Element component is rounded boulder Oligocene, Eocene and Cretaceous limestone and Firestone tough and difficult conditions in an area with sand and grit coarse sand (and semen concrete is limestone). Firestones are generally dark brown and oxidized. (Mehrnia, 2000; 2010).

Formation: thickness is about $2966 \mathrm{~m}$ distinct classes of brown and gray calcareous sandstones and (Marls) Marley (red stone) siltstone and a few streaks of gypsum are formed by weathering (Hassanipak and Ali Asghar, 2008).

Mishan Formation: include low weathered gray marls and hip or donkey stack containing shell fossils, animal species, with lots (Zomorodian-Hussein, 1998).

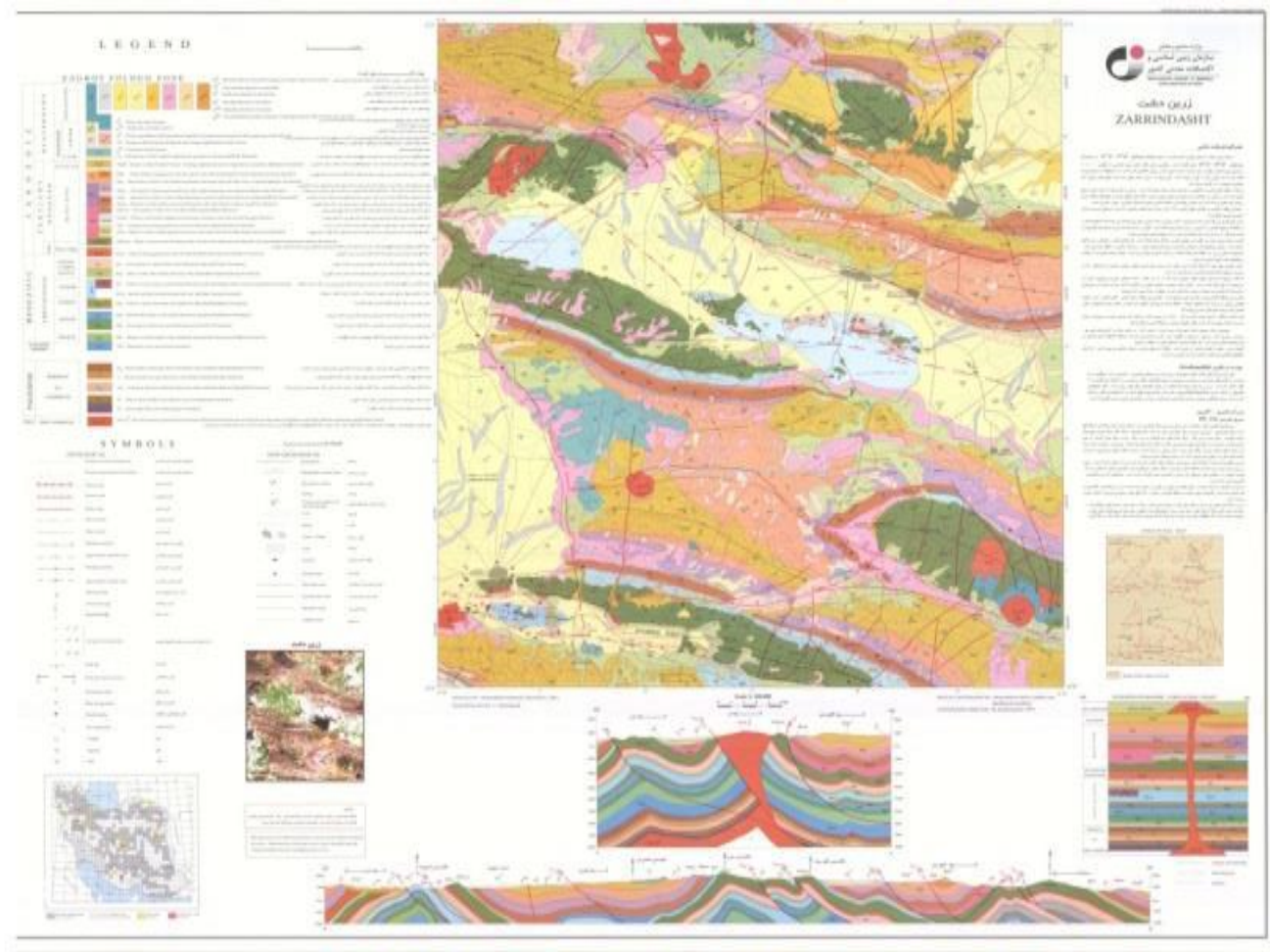

Figure-1. Regional geological setting

\section{2 .THE USE OF FRACTALS IN THE INVESTIGATION OF TIES GRAVITY}

Changes in physical quantities of land that results in the formation of various levels of anomie Field to be measured, due to differences in the formation of the corresponding component of the surface and the process of changing the nature of the anomaly coincides with a simple linear process is a complicated process. In these circumstances, traditional methods to predict the behavior of the( Euclidean) difficult and at times impossible, therefore the proposed (Darvish, 2008) for most components of the physical earth changes such as gravity, magnetic, seismic and electromagnetic mapping, allowing fractal relations for the index as a geometric Brownian 
complex environments is consistent with border Non-linear distribution coefficient anomaly after the logarithmic function (fractal dimension) namely, the fractal measure anomie in many ways has the following three characteristics:

(a) Anomaly is independent of the scale of observation and measurement device (scale independency).

(b) The interminable derived density function.

(c) Having an intrinsic component.

According to our current study (Parasnis, 1962) linear trend variables are changed by the arrival of a complex situation and repeatable components are replaced with simpler types. In practice, the complexity and ambiguity of the derivatives in turbulence, of statistical indicators (such as mean and standard deviation) not suitable for identifying and calculating the fractal dimension of the self-similar communities can best offer for the separation of the corresponding communities. Euclidean perspective, relationships between fixed and geometrically proportional to changes in the level of anomie equal level 2 it is. While the visibility of fractal geometry, the coefficient is proportional to the angle of each level, the actual numerical value is greater than 3 times the diversity and distribution mechanism, the possibility of the emergence of the peak of conventional Brownian provides reproducible quantities. In theory, fractal function derived from certain power relationships in which a logarithmic number of independent features used to determine the distribution of the dependent variables used.

\subsection{Determines the Fractal Dimension}

First place in the region identified by latitude and longitude as the center of our consideration of the central point is plotted as the radius of the semicircular create. The variance between Bouguer data for each category is said to be calculated.

Changes in nonlinear methods based on the variogram surface anomaly gravity data have been introduced.

$$
E\left[\left(z_{p}-z_{q}\right)^{2}\right]=\left(d_{p q}\right)^{2 H}
$$

Which $z_{p} \& z_{q}$ respectively reflect the cost changes depending $\mathrm{mm} \mathrm{Gal}$ at two point's $\mathrm{p}$ and $\mathrm{q}$ in terms of the anomaly and $d_{p q}$ the horizontal distance between the points mentioned in meters.

We can see that the expected value of $\mathrm{E}$ in $\left(\mathrm{z}_{\mathrm{p}}-\mathrm{z}_{\mathrm{q}}\right)^{2}$ is proportional to the distance $\mathrm{d}_{\mathrm{pq}}$ and the type of relationship they can have with the $2 \mathrm{H}$. So that we can write:

$$
2 H=3-F D
$$

To gather the classical statistical concepts, including expectation $\mathrm{E}\left[\left(\mathrm{z}_{\mathrm{p}}-\mathrm{z}_{\mathrm{q}}\right)^{2}\right]$ because of the random variables with the variance of inflation changes and is proportional to $z_{p} \& z_{q}$ in points. This means that we can write:

$$
E\left[\left(z_{p}-z_{q}\right)^{2}\right]=\frac{\sum\left(z_{i}-Z\right)}{N}
$$

In words $\Sigma\left(Z_{\mathrm{i}}-\mathrm{Z}\right) / \mathrm{N}$, in order $Z_{\mathrm{i}}$ to assess the expensive component in terms $\mathrm{Z}$ of per $\mathrm{ml} \mathrm{Gal}$ and the severity of $\mathrm{N}$ the anomaly is distinct impression. 
Results obtained from the relationship (1), (2), (3), confirming the relationship between the scattering powers of gravity changes distance placing anomaly $2 \mathrm{H}$ is proportional to the fractal dimension FD. Prerequisite for the achievement of the committee referred to in (3), geostatistical interpolation data exploration sought to create the impression of continuity and sufficient condition on the network, using logarithmic coordinates for the angular coefficient of FD is:

$$
\log V_{Z}=F D \log D_{Z}
$$

As the logarithm of the logarithm of the diffraction diagram draw distance.

With the custom function $\log \mathrm{v}-\log \mathrm{D}$, the fractal dimension FD changes reflect a desire to form a rigid shell of the Earth's ability to support the points made by the fractal properties, and show $y=m x+b$ that the least-squares regression line with their choice and we will fit the slope of the line obtained show that the fractal dimension using MATLAB programming written.

Thus, for the ideal community, Brownie Level required to form the surface often changes after $2<\mathrm{FD}<3$ is (Thorrarinsson and Magnusson, 1990) in other words, diffraction-distance relationship for those of the anomie that their fractal dimension between the numbers 2 and 3 are true.

In this study, in order to reduce the surface roughness to determine the optimal density anomaly Bouguer we thus achieve the same power that raised 1/5 to 2/5 the anomie Bouguer for various densities, out of in fractal dimension variation density is depicted turning point density by minimizing the objective function value fractal Brownian surface is used to determine the density anomaly fits the following equation Bouguer we will:

$$
B_{\text {new }}=B_{\text {old }}+\left(P_{\text {new }}-P_{\text {old }}\right)(0.5 T-0.04188 h)
$$

The order $B_{\text {new }}$ and $B_{\text {old }}$ sequence of the unknown and known anomaly in distaste Bouguer scabies, $\mathrm{P}_{\text {new }}$ and $\mathrm{P}_{\text {old }}$ the new and the old in terms of kilograms densities respectively, the density, the density of the old $1 / 5$ to $2 / 5$ Nettleton region 2 and the new densities than 5 kilograms per cubic meter, which is calculated based on the elevation angle $\mathrm{h}$ (meter) stating that the horizontal axis of the graph represents the distance in meters and the vertical axis of the anomaly in millimeters scabies Bouguer.

\section{FREE AIR ANOMALIES}

Free air anomaly on plain linear variogram hops to 7 kilo meter display indicates Razak Topography is protected by the non-fractal scaling, which is the distance over $7 \mathrm{~km}$ in the balance Isoztasi topography involved. The above chart shows that the region is under Isoztasi effect Nettleton method for short distances up to $7 \mathrm{~km}$ you can reach the appropriate density for distances over Fractal analysis must be used. Figure 2 shows a diagram of the fractal dimension. 


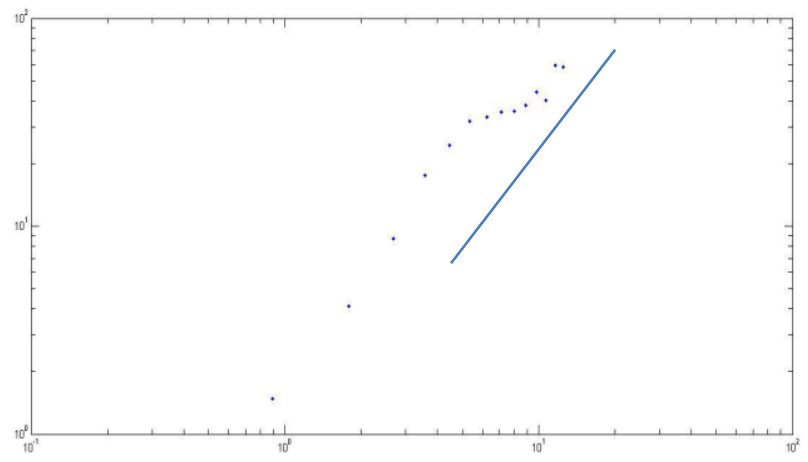

Figure-2.Linear regression to estimate fractal dimension in the free air anomaly

\section{DETERMINE THE DENSITY BOUGUER}

After reviewing the free air anomaly and elevation effects are independent of changes to prices, terms of diffraction distances for medium density $\rho=2$ anomalies Bouguer and the results are shown as figure 3. based on the above chart, the emergence of low-threshold Bouguer in the fractal-like line ratio $\mathrm{FD}<2 \mathrm{Fed}$ is bringing the quantities corresponding to the level of Brown and monitoring components (after 2.32th fractal) apparent. Thus, the density is determined by measuring the density changes only within a limited effect on the level of severity of expensiveness is possible to achieve reliable results, calculation of statistical indicators Bouguer times the density(1.5 to 2.5$)$ a necessity.

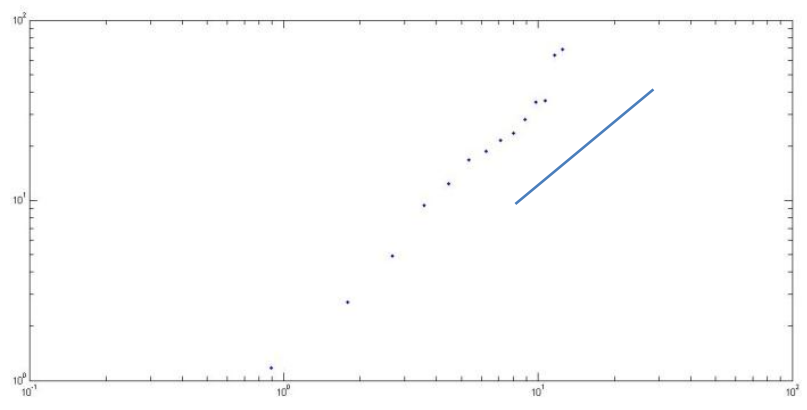

Figure-3. Linear regression Full anomaly in the density of 2

\subsection{Determine Density Regions}

To determine the optimal density in the Zareendasht (Razak plain) (the statistical methods used and the results Are shown in E.q 7 and the following equation using EXCEL software prices have been calculated for 210 data. Minimum and maximum densities of 1.5 and $2.5 \mathrm{~kg}$ per cubic meter selected.

The two-dimensional correlation with the topographic anomaly Bouguer table 1 showed that the software SPSS the anomaly and its Bouguer fractals, low correlation with topographical 
anomaly compared to the result Bouguer, Nettleton method is in accordance with the correlation table in the next two lowest density values obtained in the first super-dense downward at a density of 1.8 will be minimum density of 1.9 start again the correlation value is 0.0011 , which is a rise in the minimum density of 1.8 it is not.

Table-1.Statistical parameters for the comparison of different density anomaly Bouguer to be applied in the Golden Plains (plain Razak)

\begin{tabular}{|c|c|c|c|c|}
\hline \multirow[t]{2}{*}{ No } & \multirow[t]{2}{*}{ Density(kg/m3) } & \multirow{2}{*}{$\begin{array}{r}\text { Bouguer } \\
\text { Anomaly } \\
\text { Min }\end{array}$} & (mgal) & \multirow[t]{2}{*}{ R2P Ration } \\
\hline & & & Max & \\
\hline 1 & 1.5 & -94.139 & -63.865 & 0.044033 \\
\hline 2 & 1.6 & -97.881 & -67.292 & 0.02898 \\
\hline 3 & 1.7 & -101.371 & -70.719 & 0.013933 \\
\hline 4 & 1.8 & -104.861 & -74.146 & 0.0011 \\
\hline 5 & 1.9 & -108.35 & -77.573 & 0.0161 \\
\hline 6 & 2 & -111.84 & -81 & 0.03107 \\
\hline 7 & 2.1 & -115.33 & -84.426 & 0.04599 \\
\hline 8 & 2.2 & -118.819 & -87.853 & 0.06086 \\
\hline 9 & 2.3 & -122.309 & -91.280 & 0.07565 \\
\hline 10 & 2.4 & -125.799 & -94.607 & 0.09038 \\
\hline 11 & 2.5 & -129.289 & -98.134 & 0.10501 \\
\hline
\end{tabular}

\subsection{To Determine the Optimal Density of Fractals}

To use fractal method to evaluate the non-linear distribution of data can be expensive in terms of function (Robinson, 1988) which has already been introduced with regard diffraction distance relationship(E.q 4) in figure 4, the graph obtained from scattering length density of 1.8 for the fractal function are considered. Over time can cause the emergence of communities fractal dimensions can be varied with changes of Brownian $(2<\mathrm{FD}<3)$, anomaly identification in Bouguer independent of the height change is provided in Table 2 are considered as the next most fractals attributed to the density anomaly of 2.5 and a minimum density of $1.8 \mathrm{~kg}$ per cubic meter It is.

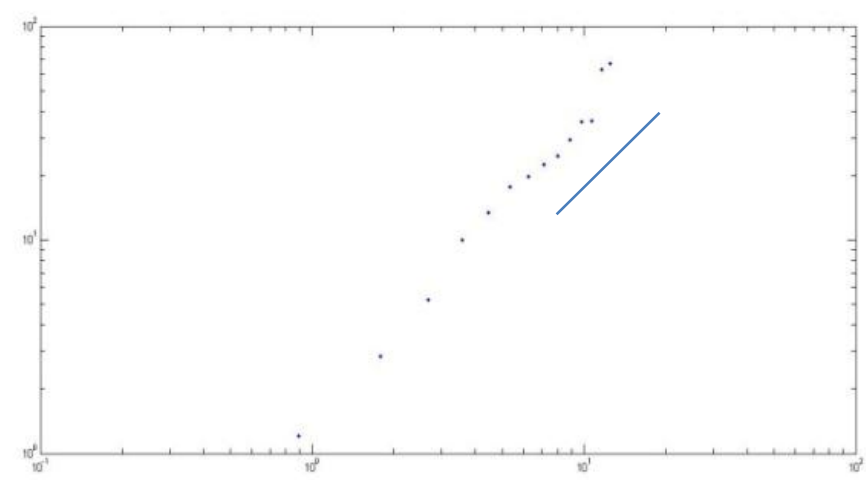

Figure-4.Linear regression Full anomaly area density of 1.8 
Table-2.The fractal dimensions determined by using the diffraction diagrams for the density range of (2.5 to 1.5$)$ kilograms per cubic m

\begin{tabular}{l|l|l}
\hline No & Density & Dimensions \\
\hline 1 & 1.5 & 2.50 \\
\hline 2 & 1.6 & 2.39 \\
\hline 3 & 1.7 & 2.28 \\
\hline 4 & 1.8 & 2.17 \\
\hline 5 & 1.9 & 2.27 \\
\hline 6 & 2 & 2.32 \\
\hline 7 & 2.1 & 2.43 \\
\hline 8 & 2.2 & 2.53 \\
\hline 10 & 2.3 & 2.65 \\
\hline 11 & 2.4 & 2.71 \\
\hline & 2.5 & 2.79 \\
\hline
\end{tabular}

Similarly, to achieve the same power density values for different pan, then the variation fractals are plotted versus density or density of a minimum quantity milestone represents the fractal dimension of Brownie level diagram is depicted in figure 5.

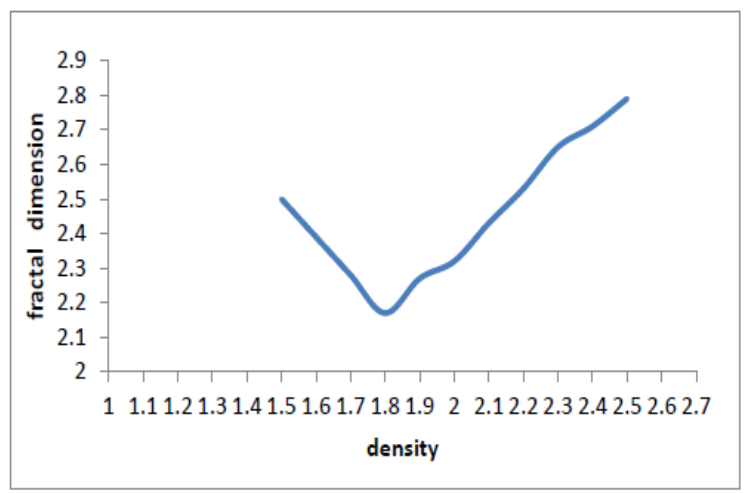

Figure-5 .Displays the optimal density region

\section{INTERPRETATION AND COMPARISON OF THE ORIGINAL AND OPTIMIZED BOUGUER ANOMALIES WITH THE TOPOGRAPHY OF THE AREA}

This section examines and compares the density anomaly Bouguer 2 grams per cubic centimeter density induced by Bouguer The optimal density of 1.8 grams per cubic centimeter is the topography of the region. According Figures 6 to 7 and one anomaly map Bouguer both very similar to each other and determines the reason for the small difference in density corrections reserved. 


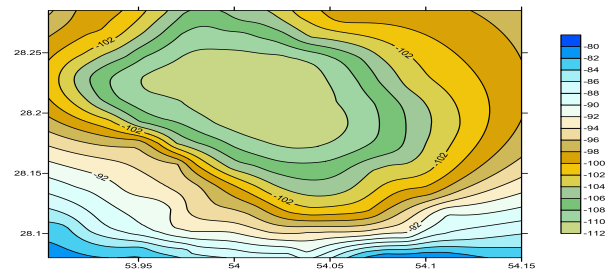

Figure-6.Full-density anomaly contour map 2

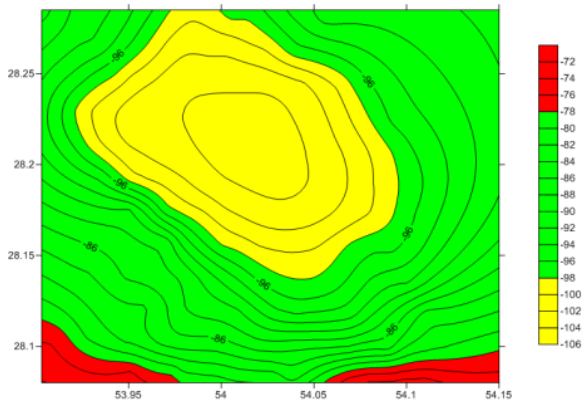

Figure-7.The optimal density anomaly contour maps 1.8

Both are steeped map centered roughly northwest and southeast. Any anomaly costume exhibit and stalagmites in the center of the map. Anomaly in two-dimensional correlation so long north-south and east-west sections also shows (that the shapes 8, 9 and 10) both east-west and north-south profiles are plotted in density has been optimized for approval.

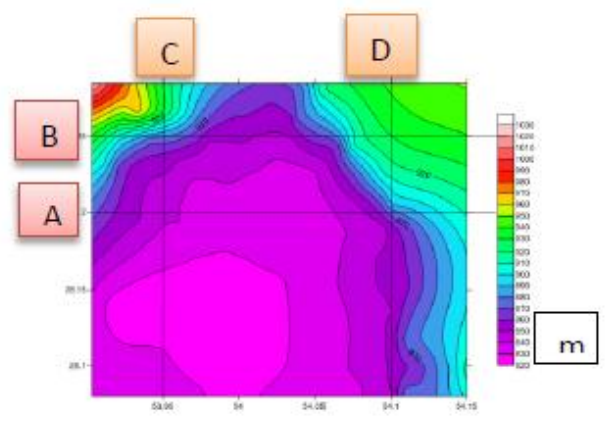

Figure-8. Profiles of graphic topographic maps

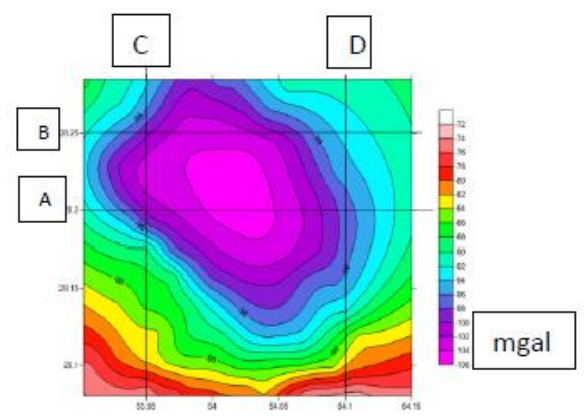


Figure-9. Profiles of graphic Bouguer anomaly map of the area

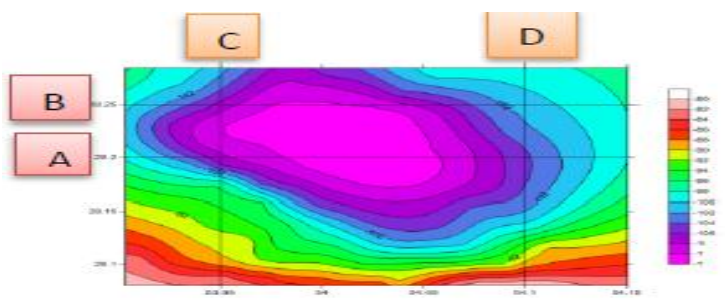

Figure-10. Profiles of graphic anomaly map Bouguer optimal harvest area

Table 3 shows the correlation between the levels mapped to topographic profiles indicate that Bouguer the optimal density anomaly maps created in the region, with more autonomy and better define the anomaly Bouguer Home area than the topography of the region is capable of and the numerical values obtained for the correlation Sections indicate that the number density of $1.8 \mathrm{~g}$ the east-west cross section and north-south cross section is less than the values obtained for the density of $2 \mathrm{~g}$ it is. Trend anomaly curves Bouguer the optimal density anomaly Bouguer little smoother than the original density (as in the southeast region). syncline also causes wrinkles and Bakhtiari Asmari that the study area is covered by quaternary sediments. Synclinal axis on the map new Bouguer anomaly is narrower, indicating the absence of double folds Asmari a gentle slope Asmari outcrops east of the western region implies.

Table-3.Correlation between the density profiles of the optimal density

\begin{tabular}{l|l|l}
\hline LINE & DENSITY $=\mathbf{2}$ & OPTIMAI DENSITY=1.8 \\
\hline $\mathrm{A}$ & 0.888684 & 0.873805 \\
\hline $\mathrm{B}$ & 0.977539 & 0.966507 \\
\hline $\mathrm{C}$ & 0.47556 & 0.452 \\
\hline $\mathrm{D}$ & 0.34827 & 0.32177 \\
\hline
\end{tabular}

Statistical comparison of the results with fractal method and the method of drawing sections confirms that the density of $1.8 \mathrm{~kg}$ per cubic meter combined with lower correlation coefficients and two-dimensional correlation is perfect for the independent status of Bouguer density zone provides topographical changes. The statistical method and the method of fractal and draw sections 1.8 density as the density of new optimization are introduced.

\section{CONCLUSIONS}

Free air anomaly represents a linear variogram has a range of $7 \mathrm{~km}$, which represents conservation topographic shell.

According to the diagram to determine the density of an anomaly changes suggest Bouguer against changes in fractal dimension the proposed method can be a sign of conformity Mark and Aronson (1984) with gravity data in the region also considering the different aspects of the graph of the density changes from 2.5 to is 2.79 , indicating changes in learned geological causes syncline, folding Asmari and Bakhtiari. 
Density anomaly contour map Bouguer comparison between 2 and 1.8 grams per cubic centimeter indicates that the two maps are significant changes and corrections to be determined because the small difference in density. The curves in the optimal density are smoother than the original anomaly and anomaly maps Bouguer central syncline new pales, indicating the absence of double folds of the Asmari Formation. According to figures obtained by graphical profiles in the region (Nettleton, 1939) known as profiles graphical anomaly map Bouguer optimal density of 1.8 grams per cubic centimeter than the graphical profiles Bouguer anomaly contour map of 2 grams per cubic centimeter less than the topography of the region.

\section{Funding: This study received no specific financial support.}

Competing Interests: The authors declare that they have no competing interests.

Contributors/Acknowledgement: All authors contributed equally to the conception and design of the study.

\section{REFERENCES}

Darvish, Z.A., 2008. Geological survey of Iran. Tehran University Press Institute.

Hassanipak and S. Ali Asghar, 2008. Exploratory data analysis. Institute of Tehran University.

Mark, D.M. and P.B. Aronson, 1984. Scale - dependent fractal, dimension of topographic surfaces. Math Geol, 16: 671-683.

Mehrnia, R., 2000. Fractal modeling approach to estimate the radius of influence of magnetic lineaments in sheet 1: 2500000 (North West of Iran).

Mehrnia, R., A. Ebrahimzadeh and W.A. Timurid, 2010. Fractal method for determining the density of the stone tablet in the quarter (Southern Iran).

Nettleton, 1., 1939. Determination of density for reduction of gravimeter observations. Geophysics, 2(3): 121124.

Parasnis, D., 1962. Principles of applied geophysics. Methuen, 7: 214-217.

Robinson, A., 1988. Principles of geophysical exploration. Translation Doctor Mohammad Reza Heydariyan city of Mashhad University Press (2001).

Thorrarinsson, F. and S.G. Magnusson, 1990. Bouguer density determination by fractal analysis. Geophysics, 5: 671-683.

Zomorodian-Hussein, M.C.H., 1998. Applied geophysics. Tehran University.

\section{BIBLIOGRAPHY}

Tontini, F.C. and P. Stefannellis, 2007. Determining the optimal bouguer density for a gravity data set. Geophysics, 10: 169-173.

Year, G., 2002. Exploration geophysics Institute of Tehran University Press.

Views and opinions expressed in this article are the views and opinions of the author(s), International Journal of Geography and Geology shall not be responsible or answerable for any loss, damage or liability etc. caused in relation to/arising out of the use of the content. 